\title{
Studying the Failure Behavior of Cement-fiber-treated Sand under Triaxial Direct Tension Tests
}

\author{
Behzad Isazadeh-Khiav ${ }^{1 *}$, Tohid Akhlaghi ${ }^{1}$, Masoud Hajialilue-Bonab \\ ${ }^{1}$ University of Tabriz, Department of Civil Engineering, University of Tabriz, 29 Bahman Blvd, Tabriz 5166616471, Iran \\ * Corresponding author, e-mail: b.isazadeh@tabrizu.ac.ir
}

Received: 02 May 2021, Accepted: 22 December 2021, Published online: 12 January 2022

\begin{abstract}
The main goal of this research is to study the failure behavior of cement-fiber-treated sand under triaxial direct tension condition tests. Thus, a new loading system and triaxial cell was designed and built for tensile loading. Samples were prepared with content cement of 3 and $5 \%$ (dry wt.) of the sand, while two types of polypropylene fibers $0.024 \mathrm{~m}$ in length and $23 \mu \mathrm{m}$ and $300 \mu \mathrm{m}$ thick were added at $0.0 \%$ and $0.5 \%$ (dry wt.) of the sand and cement mixture. After a seven-day curing period, the samples were loaded under triaxial direct tension tests under confining pressures of 100, 200, and $300 \mathrm{kpa}$ in drained conditions. Stress-strain behavior, changes in volume and energy absorbed by cement-fiber reinforced sand were measured and compared with the results of other studies. Adding fibers resulted in reduced peak deviatoric stress and increased residual deviatoric stresses of the cement-fiber reinforced sand, with changes from brittle to ductile behavior. The initial stiffness and stiffness at 50\% maximum tensile stress of the samples is decreased with the addition of fibers and with an increase in fiber diameter, the reduction rate of this stiffness is more evident. The absorbed energy for fibers with a thickness of $23 \mu \mathrm{m}$ is less than fibers with a thickness of $300 \mu \mathrm{m}$. The effect of adding fibers to strength parameters showed that the cohesion intercept decreases, while the internal friction angle increases.
\end{abstract}

Keywords

cement-treated sand, artificial fibers, triaxial direct tension, strength parameters

\section{Introduction}

Nowadays, with regard to the acceptance and utilization of economical additives in problematic soil, construction on loose and soft soils has also had significant growth. From many years ago, different techniques have been used for refining the mechanical characteristics of soil, such as the injection of calcium oxide, cement, tar and etc. Today, new additives such as nano-materials and artificial polymers have resulted in the development of physical and mechanical features of the cement-soil system more than ever before. One of the important issues in designing geotechnical structures related to the cement-soil system is tensile stress from bending moment, which expands in these structures. Following dynamic experiments on centrifuge models and also finite element analysis on lattice-shaped walls with adequate performance in reducing liquefaction, it is observed that by creating strong shaking events, tensile cracks appear in the cement-soil wall resulting from bending. These observations signify the importance of evaluating the tensile behavior on cement treated soil in the cement-treated column design process and the lattice-shaped walls. Therefore, in order to prevent failure and weakness resulting from cement-treated soil under tension, one of the suggested methods is to use new additives such as artificial fibers. For example, in stabilizing the cement-treated soil column and lattice-shaped ground improvement, which are usually used for reducing the construction costs, bending tensile failure created from external loads in the cemented soil are the main factors in the stabilization plan of these soil types $[1,2]$.

In addition, regarding the centrifuge model experiments for soil columns stabilized with cement under embankment loading, it was observed that due to the tension mechanism created from bending, bending tensile failure is induced in the cement-treated columns because of the embankment loading. Soil stabilization has been achieved through lattice-shaped walls by using cement as the method to reduce liquefaction. The adequate performance of this method was proven in 1995 during the Hyogo-ken Nanbu earthquake. 
Research conducted and the finite element analyses have shown that high magnitude earthquakes enhance tensile rupture in the corners of lattice-shaped walls. [3]

Also, dynamic centrifuge experiments to evaluate strengthening factors of lattice-shaped walls in the cementsoil system on the seismic response of soft soil profiles carried out at depth indicate the strong movement to be the reason for tensile cracks in the cement-soil wall [4].

The creation and expansion of cracks in material containing cement results in techniques that can be considerably helpful in improving the behavior of composite material containing cement. One of these techniques is the addition of artificial fibers to the composite system. Artificial fibers are considered as reinforcement elements and result in reduced cracking. Observations made from research show that artificial fibers do not only directly control the cracking, but also improve the post-cracking mechanical properties. Such techniques are significant due to improved mechanical properties of soil, such as increased shear resistance, ductility, energy adsorption, strength against fatigue and impact $[5,6]$.

Stabilization of soil by means of cement has been extensively used for structural foundations, exclusion methods against liquefaction, retaining walls during excavation, and other cases. Extensive studies have been conducted by numerous researchers in this field [7-10]. Most of these studies are based on results from triaxial compression tests which indicate that with an increase in the percentage of cement in soil, its brittleness and dilative behavior will increase until the point of peak shear strength and by increasing confining pressure, the behavior will tend towards strain softening. [11-14].

According to a study conducted by Namikawa and Koseki [15], by using numerical simulation on three types of direct tension, splitting tension and bending tests, and by designing a new tool for measuring concrete tension resistance in a study carried out by Sarafrazi et al. [16], it was shown that the direct tension test yields more realistic results compared to other methods. In order to show the failure criterion of cement-treated soils under tensile behavior, it is necessary to conduct experimental tests so that tensions can be adequately controlled in three-dimensional conditions. Therefore, in 2017, the failure behavior of cement-treated soil under triaxial tension tests was carried out by Namikava et al. [17]. Overall results of their experiments showed that the stress strain relationship of the drained triaxial tension tests with high confining pressure (at about $400-500 \mathrm{kpa}$ ) is similar to triaxial compression tests at low confining pressure. In fact, it can be concluded that the failure of cement-treated soil in the above-mentioned conditions occurs at shear mode.

The behavior of fiber-reinforced sand has also been studied by some researchers [18-20]. The results of these studies show that adding fibers to sandy soils results in enhancing the peak shear strength level and also increases soil ductile behavior [21-24].

The simultaneous effects of both cement and fibers on the mechanical behavior of sandy soil have been studied by a group of researchers [25-34], among which the work by Consoli et al. [26-30, 34] can be referred to. In their study, by conducting triaxial compression tests it was observed that adding fibers to cemented soil could increase peak and residual shear strength and reduce residual dilation [25-28]. Overall, artificial fibers are resistant towards tensile rupture and have considerable features in improving composite material ductility [32-34]. In 1993, Maher and Ho [25] have reported a number of studies regarding the effect of cement and artificial fibers on the mechanical behavior of sandy soils. They have conducted static and dynamic triaxial compression tests and the Brazilian test on cementtreated sands with randomly distributed artificial fibers and reported the highest shear strength and energy absorption for fiber containing soils. In addition, by carrying out split tensile tests in 2011, Consoli et al. [34] showed the effect of porosity and cement and the voids/cement ratio on evaluating cement-treated soil tensile strength with and without fibers. Their results indicated that adding fiber results in enhancing split tensile strength [34]. This study is among the very few studies conducted on evaluating sand tensile strength reinforced with cement and fibers.

In all previous studies related to evaluating compressive strength and specifically tensile strength, the effect of confining pressures and also direct tensile strength of cemented samples and those with added fibers were not considered and were not evaluated. Overall, artificial fibers are strength towards tensile failure and fracturing and have considerable features in improving composite material ductility. Therefore, the aim of this research with regard to lattice-shaped ground improvement and cement-treated soil columns, which are stabilized by cement-soil systems, is failure due to governing tension. Also, implementing this system at great depths, simulating soil elements in-depth, and evaluating the effect of confining pressures of soil in this type of study by using triaxial tests is more appropriate. In this study, in order to increase the cement-soil system, tensile strength polypropylene polymer fibers were used. 
As indicated by Namikawa et al. [17], using triaxial direct tension tests shows that the percentage of cement and confining pressure in tensile and shear failure mode are effective. In this study, with regard to adding polypropylene fibers to the samples, the drained triaxial tension test was carried out in order to evaluate the tensile and shear failure mode, peak and residual tensile strength, changes in volume, and determining The initial stiffness of the sample against variables such as changes in fiber diameter, confining pressure, percentage of fiber and cement on deviatoric stress-axial strain behavior and changes in volumetric strain-axial strain, The brittleness index, and energy absorption potential of this type of composite materials.

\section{Experimental process}

\subsection{Sand, cement and fiber}

The sand used in this research is uniform sand from the city of Ardebil, Iran, which was used after washing and drying. Fig. 1 shows granulated sand obtained at $\mathrm{CC}=1$ and $\mathrm{CU}=2.3$ according to ASTM standard [35]. Therefore, poorly graded sand is categorized with the group symbol $(s p)$.

The cement used is of Portland Pozzolana Type I from Ardebil Cement factory, the physical and mechanical characteristics of which are given in Table 1. Two types of polypropylene fiber have been used in order to evaluate the effects of fiber diameter in these experiments

In this study, two types of fibers with different diameters were used. Both fibers have a specific weight of $0.91 \mathrm{~g} / \mathrm{cm}^{3}$, length of $24 \mathrm{~mm}$, tensile strength of $400000 \mathrm{kpa}$, Type I fiber thickness of $23 \mu \mathrm{m}$ and Type II fiber thickness of $300 \mu \mathrm{m}$. Macro synthetic fibers are made of refined polyolefin polymers, but micro synthetic fibers are made of 100 percent polypropylene polymer. The most distinctive features are their diameter, tensile strength, the aspect ratio of fiber (length/diameter), number per $\mathrm{kg}$ according to Table 2.

\subsection{Sample preparation process}

The amount of sand and cement needed for each sample was combined with 10 percent kaolin clay and $20 \%$ distilled water; cement weight was calculated at 3 and $5 \%$ of the weight of dry sand and weight of fibers at 0 and $0.5 \%$ of the dry sand and cement weight and was added in equal portions to the sand and cement mixture. In the preparation phase, distilled water was initially added to the kaolin, and after the homogenous suspension was formed, it was added to the mixture of dry cement and sand. Clay was used as prevention for the separation of sand particles with a probability of passing through the 200 sieves at less than $2 \%$ so that the resulting mixture would be homogenous [17].

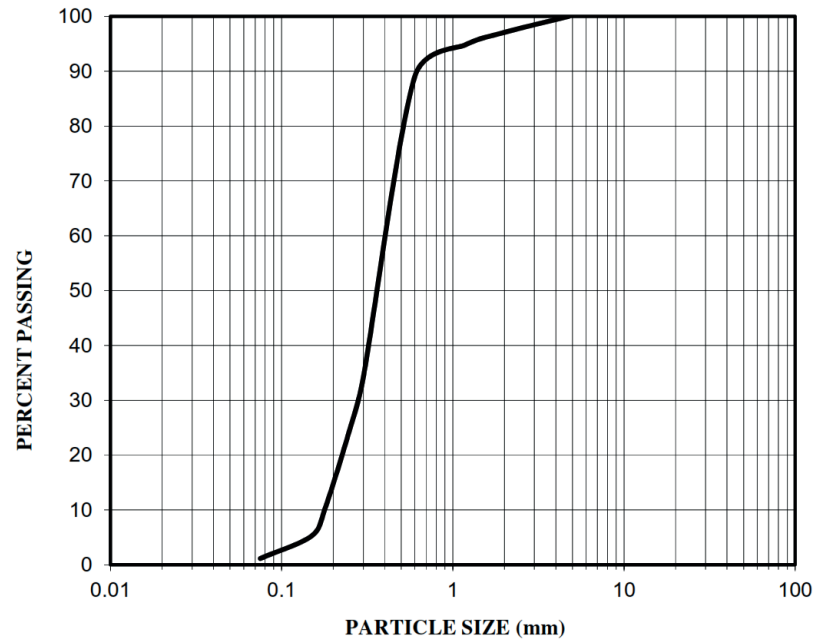

Fig. 1 Gradation curve of the base soil

Table 1 Physical properties of Cement

\begin{tabular}{lc}
\hline Object & Range \\
\hline Autoclave & 0.2 \\
Blain & 3000 \\
& Setting Time (min) \\
Initial & 120 \\
Final & 180 \\
& Compressive strength (MPa) \\
3 days & 220 \\
7 days & 320 \\
28 days & 400 \\
\hline
\end{tabular}

Table 2 Physical properties of Fiber

\begin{tabular}{lcc}
\hline Typing & Fiber type I & Fiber type II \\
\hline Material & Micro Synthetic & Macro Synthetic \\
Tensile Strength & $400000 \mathrm{kpa}$ & $570000-660000 \mathrm{kpa}$ \\
Diameter & $23 \mu \mathrm{m}$ & $300 \mu \mathrm{m}$ \\
Aspect Ratio & $600-1200$ & $30-120$ \\
Number per kg & $<100000000$ & 53800 \\
Color & Glossy white & Gray \\
\hline
\end{tabular}

In this study, the density method proposed by Ladd [36] was used. The sample was prepared in eight layers and the composite soil of each layer was calculated and condensed until reaching the objective density. [36]

After being combined in one split cylindrical mold according to Fig. 2 using the vibration method, they were compressed. The mold height is $140 \mathrm{~mm}$, with a diameter of $50 \mathrm{~mm}$ at the front and end of the mold and $45 \mathrm{~mm}$ in the middle. The length of the sample with a thickness of $50 \mathrm{~mm}$ is $25 \mathrm{~mm}$ and the section with $45 \mathrm{~mm}$ thickness is $50 \mathrm{~mm}$ long. The length of the section in which diameter changes from $50 \mathrm{~mm}$ to $45 \mathrm{~mm}$, is considered as $20 \mathrm{~mm}$. Specimen geometry is shown in Fig. 3. 
Samples were cured for five days after being removed from the mold in wet conditions and were kept in distilled water for 24 hours in order to increase their saturation level. In the triaxial drained experiment, samples are isotropically consolidated for approximately one day in order for the curing time to reach seven days. The uniaxial tensile strength (without confining pressure) of the provided samples has been obtained using the above method, with an added day of curing time as shown in Table 3.

\subsection{Experimental setup}

The image of the device used in the tensile test is schematically given in Fig. 4. In fact, this device was initially designed by Koseki et al. [37] and in this study, with changes in loading systems, pressure cell and measurement system of strain and volume change are re-designed. In this device,

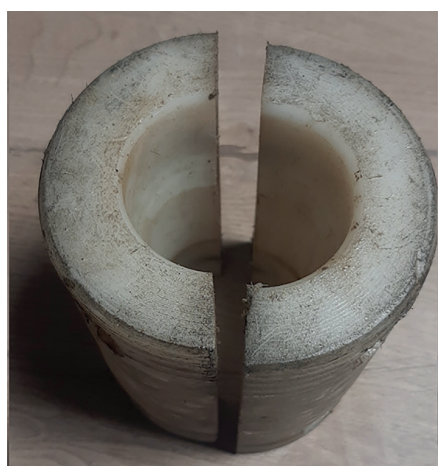

Fig. 2 Split cylindrical mold

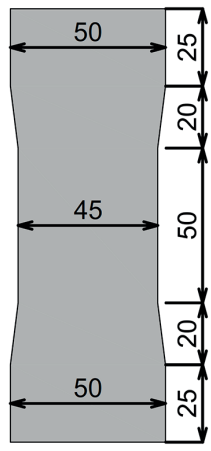

Unit(mm)

Fig. 3 Specimen geometry

Table 3 Summary of uniaxial tensile strength test results in present study

\begin{tabular}{lccc}
\hline $\mathrm{CC}^{\mathrm{a}}$ & $\mathrm{FC}^{\mathrm{b}}$ & $\mathrm{TF}^{\mathrm{c}}$ & $T_{f}(\mathrm{kpa})$ \\
\hline 3 & 0 & - & 44 \\
3 & 0.5 & $\mathrm{I}$ & 41 \\
3 & 0.5 & $\mathrm{II}$ & 39 \\
5 & 0 & - & 104 \\
5 & 0.5 & $\mathrm{I}$ & 95 \\
5 & 0.5 & $\mathrm{II}$ & 90 \\
\hline
\end{tabular}

${ }^{\mathrm{a}}$ Cement content.(\%); ${ }^{\mathrm{b}}$ Fiber content.(\%); ${ }^{\mathrm{c}}$ Type fiber the specimen is placed between two holders. Gypsum is used as an adhesive material for filling the gap between the specimens and the holder in order to transmit tensile forces during the loading process. The holders are connected to the upper and lower base with ball joint connections in order to prevent a bending moment on the specimen.

As it was previously mentioned, the direct tensile test has more realistic results compared to cement-treated sand tensile strength. [19] In order to reduce error resulting from shaft bearing friction and the cover above the cell from the two-part sealing system, an oring was placed at the bottom and in the inner wall of the covering. The tensile force was measured by using an external electronic power meter. Axial displacement is achieved by Linear Variable Differential Transformer (LVDT) and the cross-sectional area of the sample is modified according to the axial strain. Changes in the volume were evaluated using the Burrette volumetric measuring device due to insignificant changes in the sample volume from tensile forces, whereas back-pressure is applied in this device. The figure of the device used during the triaxial tensile test is provided in Fig. 5.

After placement in the cell, the sample is surrounded a latex membrane and then saturated using the double vacuuming method or dry setting method [38].

All specimens reached saturated conditions by applying back pressures between 190 to $240 \mathrm{kPa}$. Skempton's B-value obtained for all experiments was at least 0.75 [39].

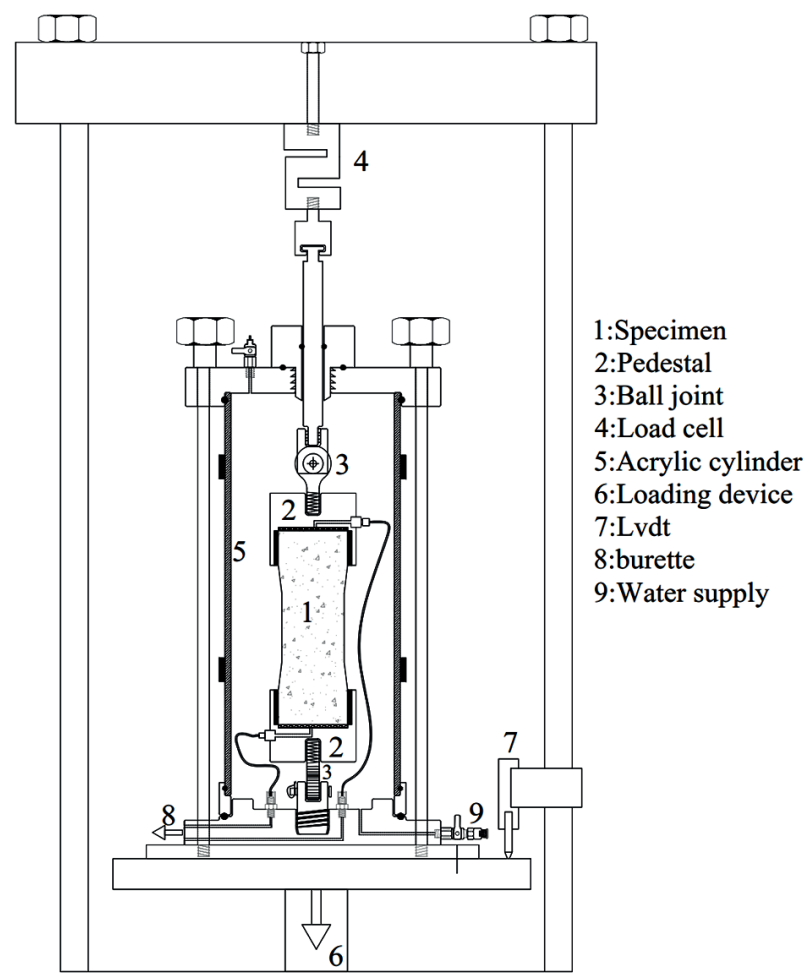

Fig. 4 Schematic diagram of the triaxial tensile test device 


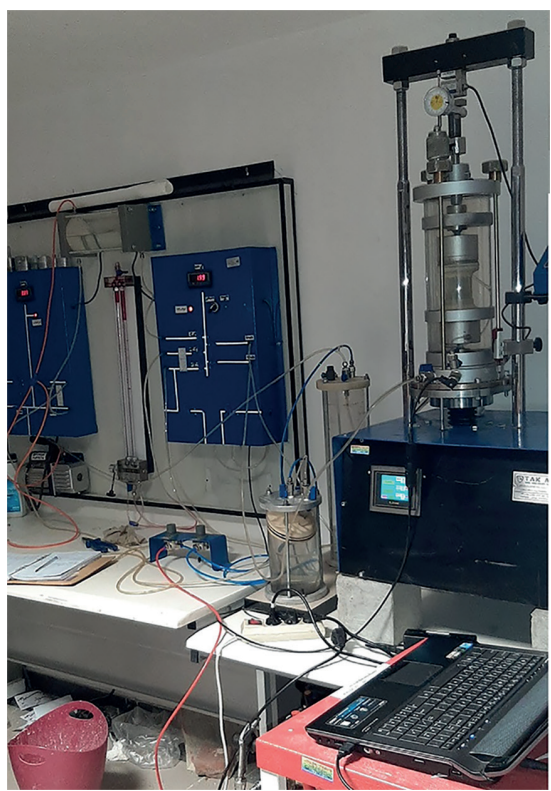

Fig. 5 Triaxial tensile test device pressure was applied at 100, 200 and $300 \mathrm{kPa}$. Then, at a very low loading rate of $0.005 \mathrm{~mm} / \mathrm{min}$, they were loaded in drainage form. In order to prevent excess pore pressure during loading, the loading rate was considered at a minimum and an attempt was made to stabilize the pore pressure during loading.

\section{Experimental results}

In this study, the cement-fiber-treated sand tensile behavior was evaluated using triaxial direct tension tests. The summary of these tests is provided in Table 4. Overall, 23 experiments were conducted, a number of which were repeated for validation. In Table 4 , the amount of diviatoric stress $(q)$ and mean stress $\left(p^{\prime}\right)$ are calculated according to Eq. (1) and Eq. (2) below, in which $\sigma_{1}{ }^{\prime}$ is effective major stress and $\sigma_{3}{ }^{\prime}$ is minor principal stress:

$$
q=\sigma_{1}^{\prime}-\sigma_{3}^{\prime},
$$

$p^{\prime}=\frac{\sigma_{1}^{\prime}+2 \sigma_{3}^{\prime}}{3}$ imental specimens were consolidated for 24 hours in isotropic pressure. In all experiments, effective confining

Table 4 Summary of triaxial direct tension test results in present study

\begin{tabular}{|c|c|c|c|c|c|c|c|c|c|c|c|}
\hline \multirow{2}{*}{$\mathrm{CC}$} & \multirow{2}{*}{$\mathrm{FC}$} & \multirow{2}{*}{$\mathrm{TF}$} & \multirow{2}{*}{$\mathrm{CP}^{\mathrm{a}}$} & \multicolumn{2}{|c|}{ Deviatoric stress (kpa) } & \multicolumn{2}{|c|}{ Mean stress (kpa) } & \multicolumn{2}{|c|}{ Volumetric strain (\%) } & \multicolumn{2}{|c|}{ Axial strain (\%) } \\
\hline & & & & At failure & Residual state & At failure & Residual state & At failure & Residual state & At failure & Residual state \\
\hline 3 & 0 & - & 100 & -196 & -104 & 35 & 65 & -0.037 & -0.45 & -0.41 & -1.07 \\
\hline 3 & 0 & - & 200 & -277 & -191 & 108 & 136 & 0.035 & -0.86 & -0.45 & -1.32 \\
\hline 3 & 0 & - & 300 & -365 & -278 & 178 & 207 & 0.029 & -0.22 & -0.49 & -0.89 \\
\hline 3 & 0 & - & 300 & -364 & -282 & 179 & 206 & 0.060 & -0.10 & -0.46 & -0.73 \\
\hline 3 & 0.5 & I & 100 & -172 & -160 & 43 & 47 & -0.601 & -1.61 & -0.61 & -1.51 \\
\hline 3 & 0.5 & I & 200 & -258 & -240 & 114 & 120 & -0.303 & -1.21 & -0.66 & -2.18 \\
\hline 3 & 0.5 & I & 300 & -311 & -293 & 196 & 202 & -0.031 & -1.35 & -1.00 & -3.26 \\
\hline 3 & 0.5 & I & 200 & -245 & -222 & 118 & 126 & -0.330 & -1.45 & -0.77 & -2.33 \\
\hline 3 & 0.5 & II & 100 & -148 & -123 & 51 & 59 & -1.800 & -1.80 & -1.40 & -4.50 \\
\hline 3 & 0.5 & II & 200 & -239 & -192 & 120 & 136 & -1.050 & -1.43 & -2.06 & -4.39 \\
\hline 3 & 0.5 & II & 300 & -320 & -292 & 193 & 203 & -1.190 & -1.60 & -2.51 & -4.76 \\
\hline 5 & 0 & - & 100 & -211 & -95 & 30 & 68 & -0.229 & -0.66 & -0.58 & -1.01 \\
\hline 5 & 0 & - & 200 & -346 & -164 & 85 & 145 & -0.100 & -0.63 & -0.44 & -1.25 \\
\hline 5 & 0 & - & 300 & -431 & -240 & 156 & 220 & -0.050 & -0.53 & -0.56 & -1.46 \\
\hline 5 & 0 & - & 200 & -316 & -172 & 95 & 143 & -0.090 & -0.43 & -0.42 & -1.22 \\
\hline 5 & 0 & - & 300 & -450 & -232 & 150 & 223 & -0.050 & -0.33 & -0.55 & -1.47 \\
\hline 5 & 0.5 & I & 100 & -186 & -165 & 38 & 45 & 0.110 & -1.62 & -0.38 & -3.02 \\
\hline 5 & 0.5 & I & 200 & -333 & -313 & 89 & 96 & 0.120 & -0.99 & -0.70 & -3.03 \\
\hline 5 & 0.5 & I & 300 & -406 & -369 & 165 & 177 & 0.110 & -1.06 & -0.68 & -5.54 \\
\hline 5 & 0.5 & II & 100 & -191 & -157 & 36 & 48 & -2.160 & -2.68 & -5.86 & -9.97 \\
\hline 5 & 0.5 & II & 200 & -299 & -267 & 100 & 111 & -1.860 & -2.00 & -8.58 & -11.56 \\
\hline 5 & 0.5 & II & 300 & -364 & -328 & 179 & 191 & -0.900 & -1.80 & -8.89 & -12.09 \\
\hline 5 & 0.5 & II & 200 & -322 & -256 & 93 & 115 & -2.150 & -3.10 & -4.77 & -7.20 \\
\hline
\end{tabular}

${ }^{\mathrm{a}}$ Confining pressure 


\subsection{Mode of failure}

Fig. 6 shows the impact of effective variables on failure and increase in shear band. As it is seen, in both specimens without fibers, the fracture surfaces of the specimens are approximately perpendicular to the applied tensile stress, which shows that the fracture mode might be of tension type. In case of an increase in confining pressure this behavior would probably transform from tensile fracture to shear fracture. The shear bandwidth in all cement-treated samples increases due to added fibers and fiber thickness increases due to strain localization. It should be noted that fibers in combination with cement begin to operate after certain displacement. On this basis, in samples with Type II fibers, due to the increase in surface contact with soil particles and involvement of fibers with tensile forces, they begin to stretch and with regard to the content of the cement bond with fibers, other parts of the sample are placed under tension and result in multiple fractures. In this type of fracture, while the shear band has a slope, its width also increases. In type II fibers, the shear bandwidth reduces with an increase in cement and rises with an increase in confining pressure. a

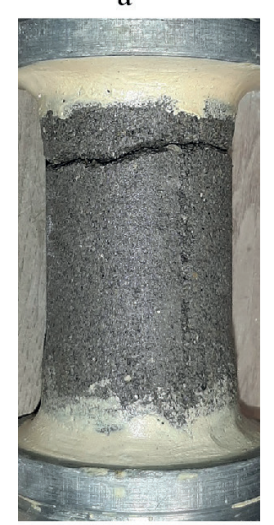

d

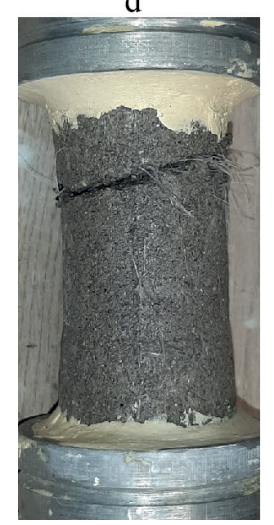

$\mathrm{b}$

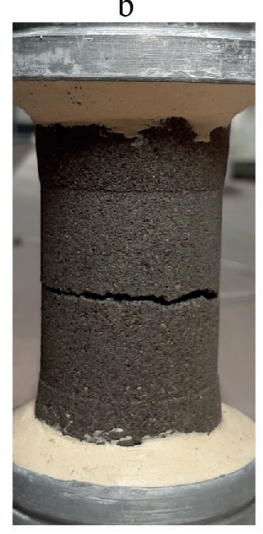

e

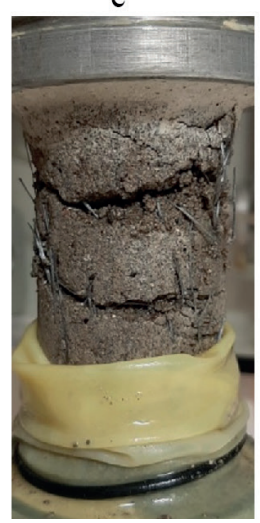

C

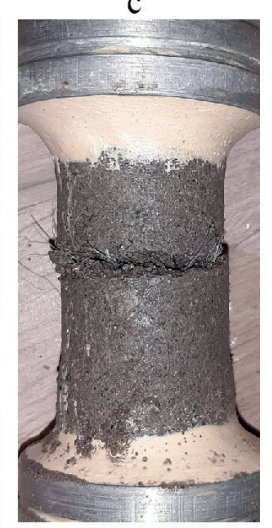

f

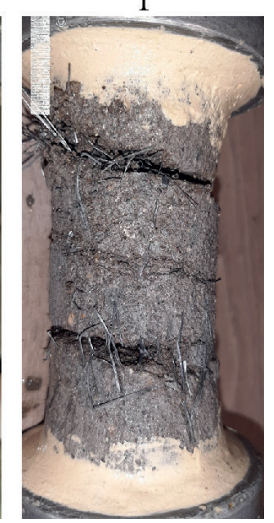

Fig. 6 Fracture mode: (a) $\mathrm{CP}=300 \mathrm{Kpa}, \mathrm{CC}=3.0 \%, \mathrm{FC}=0.0 \%$; (b) $\mathrm{CP}=300 \mathrm{Kpa}, \mathrm{CC}=5.0 \%, \mathrm{FC}=0.0 \%$; (c) $\mathrm{CP}=200 \mathrm{Kpa}$, $\mathrm{CC}=3.0 \%, \mathrm{FT}=\mathrm{TYPE} \mathrm{I}$; (d) $\mathrm{CP}=300 \mathrm{Kpa}, \mathrm{CC}=5.0 \%$, FT $=$ TYPE II; (e) $\mathrm{CP}=100 \mathrm{Kpa}, \mathrm{CC}=3.0 \%, \mathrm{FT}=\mathrm{TYPE} \mathrm{II}$; (f) $\mathrm{CP}=200 \mathrm{Kpa}$, $\mathrm{CC}=5.0 \%, \mathrm{FT}=\mathrm{TYPE} \mathrm{II}$
It can be concluded that in order to use maximum tension capacity in cemented-soils with an increase in cement percentage, fiber diameter also increases accordingly.

\subsection{Stress-strain and volume change behavior}

The axial stress-strain curve and volumetric strain-axial strain curve diagrams of all experiments are shown in Figs. 7 and 8 based on the percentage of cement and type of fiber. According to these results, it can be concluded that the initial stress-strain relationship related to all diagrams has a similar curve. Fracture type in cement-treated sand without fiber is similar in both cements at 3\% and 5\%. In these specimens, after initial hardening-strain, the diagram reaches a peak state at strain of less than $0.5 \%$ and is suddenly fractured and shows brittle behavior. Basically, the bonded structure effects include an initial hardening behavior and then an increasing plastic deformation, which eventually results in soil fracture.

However, this mechanical behavior of composite soils has been shown by Consoli et al. [27] for the compression condition. With regard to the essence of fiber, introducing fibers to cement composites might reduce to fracture and this effect enhances by applying longer fibers. Also, Stacho et al. [40] showed that adding geogrid to grained materials reduces shear strength and increases deformation. As it is observed in Figs. 7 and 8, adding fibers results in reduced peak for fiber specimens. A possible explanation for this condition is that increasing fiber length in soil can result in increased surface contact between soil and fiber and hence more fortification due to the friction between fiber and soil. On the other hand, by adding fibers such as polypropylene along with cement, part of the pores was filled with fiber instead of cement and the hardening resulting from cement decreases due to reduced cement bonds between soil grains.

The effect of fiber diameter in sections $b$ and $c$ of Fig. 7 and Fig. 8 shows that with an increase in fiber diameter, the brittleness rate resulting from cement is reduced. In Fig. 8(b), due to the high content of cement bond in $5 \%$ cement and the low diameter of type I fiber, brittle behavior resulting from cement has a relatively stronger effect and the curve has a peak similar to sample without fiber and after sudden fracture, matrix interface fibers get involved and the extensible fibers result in elongation and increased residual strength. This fracture mode was not observed in thicker type II fibers. Fig. 8(c) indicates that due to strain localization on the fracture point of the sample and coordinated bearing by both sections of the cement bond and fiber involvement, behavior becomes considerably more flexible. 

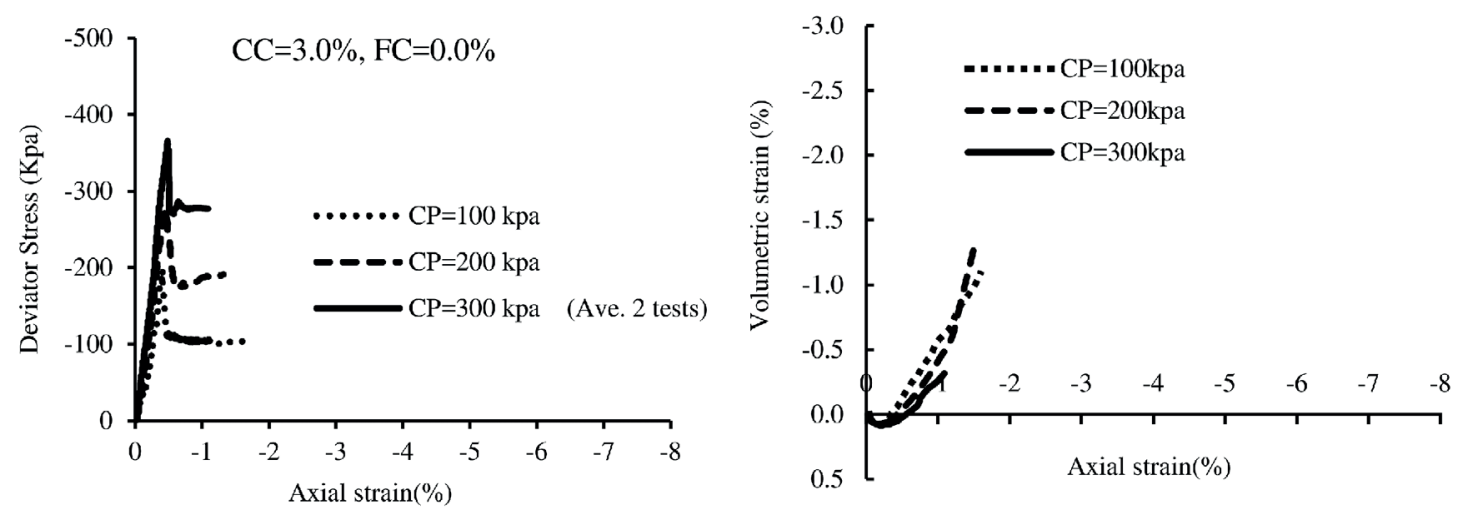

(a)
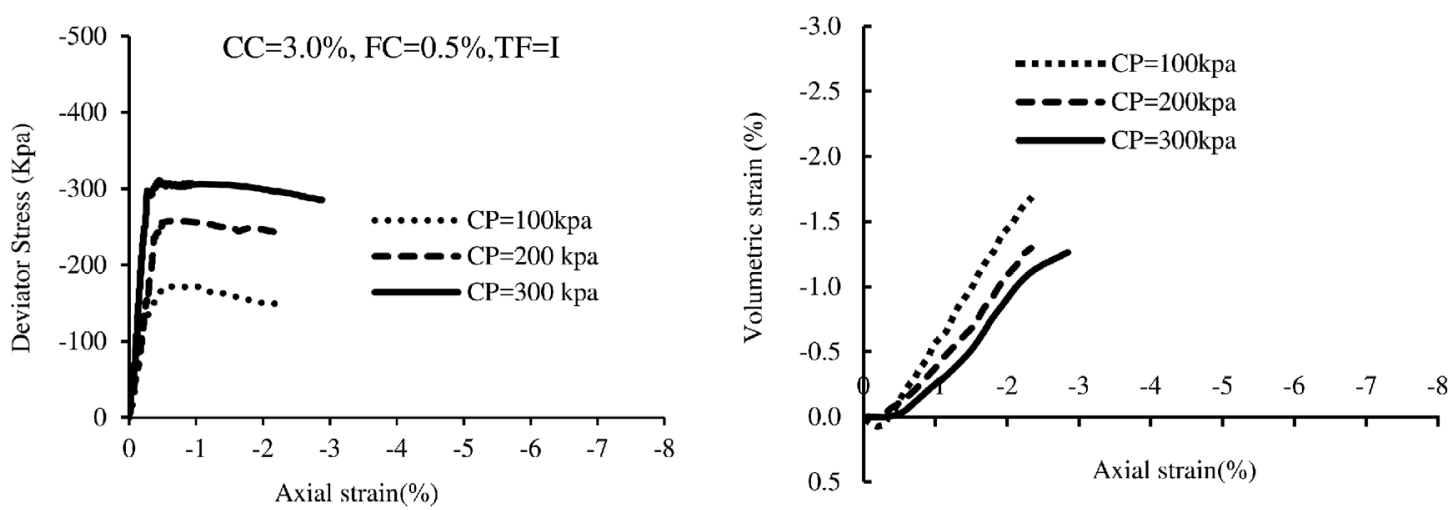

(b)
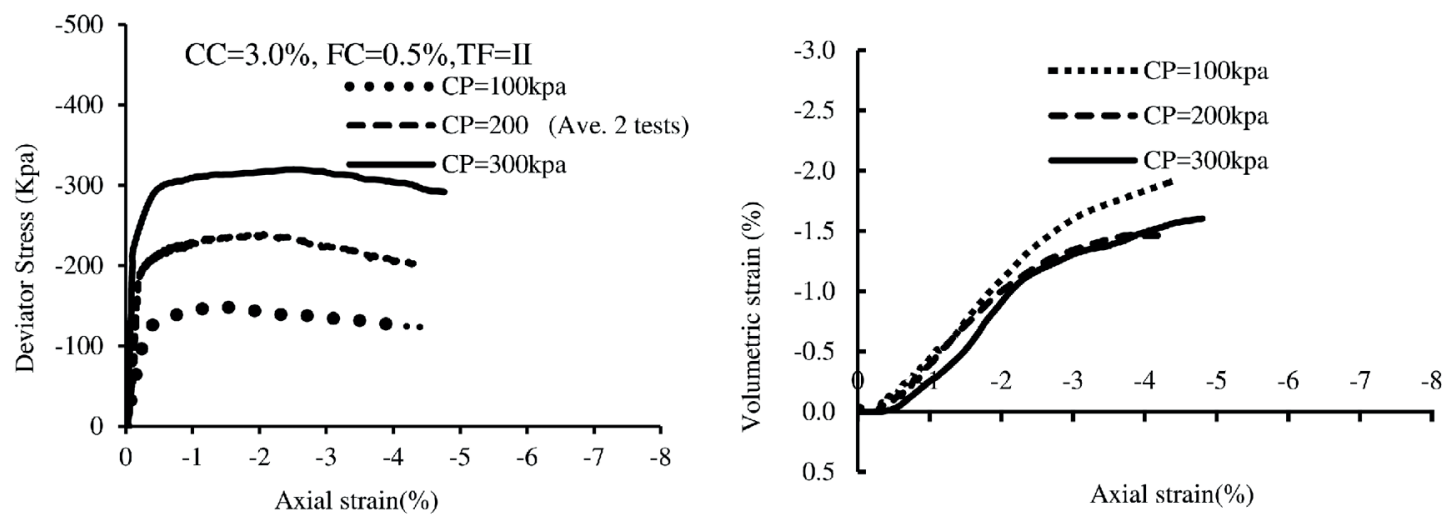

(c)

Fig. 7 Stress-strain and volume change behavior with $3.0 \%$ cement; (a) FC=0.0\%; (b) FC =0.5\%, TF = I; (c) FC = $0.5 \%$, TF $=\mathrm{II}$

Evaluation of final residual strain shows that the existence of polypropylene fibers results in its increased amount in cement-treated sands and the greater the diameter of fibers, this rate also increases due to increased surface contact of fiber with soil grains, while the absorbed energy and hence cemented soil ductility also increases.

In a comparison of sections related to volumetric strain and changes in axial strain in Fig. 7 and Fig. 8, it can be observed that samples show a very insignificant dilative behavior and after failure the increase in samples volume behavior increases similar to the axial strain. The greater the increase in percentage of cement, diameter of fiber and confining pressure, the volumetric strain axial-strain curves become flatter.

The brittleness index $\left(I_{B}\right)$ defined by Consoli et al. [26], which is presented as the Eq. (3), can be an index for evaluating the brittle behavior of materials used:

$I_{B}=\frac{q_{\max }}{q_{\mathrm{res}}}-1$. 
In which $q_{\max }$ and $q_{\text {res }}$ are the peak and residual deviatoric stresses, respectively. The relationship between brittleness index and confining pressure with regard to percentage of cement and type of fiber is shown in Fig. 9. Both figures show that with an increase in confining pressure, the brittleness index decreases, specifically for cementtreated sand without fiber, and this reduction is not significant when the fibers are added. In Fig. 9(a), for sand with $3 \%$ cement and fiber, the brittleness index in a confining pressure of $100 \mathrm{kPa}$ is less than $200 \mathrm{kPa}$, which is due to tearing of the membrane during experimentation.
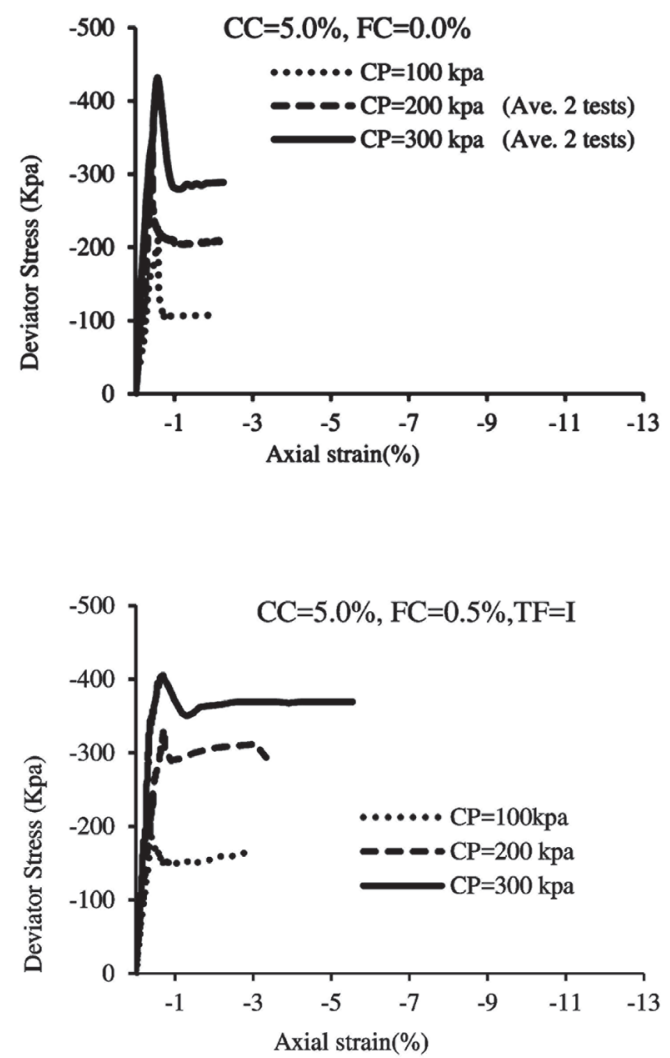

(a)
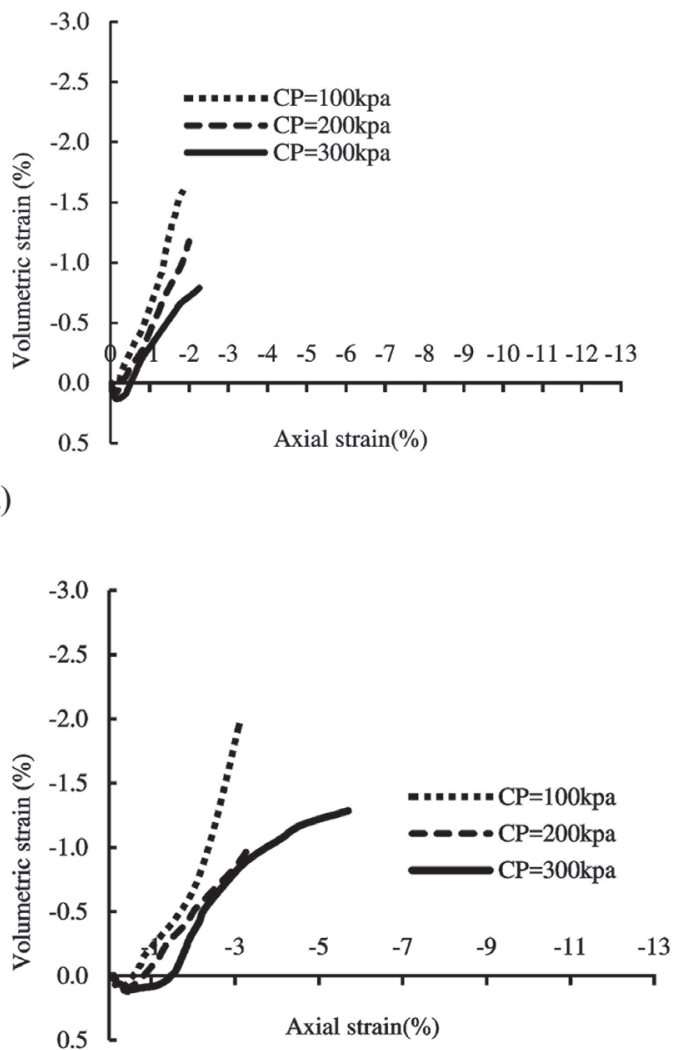

(b)
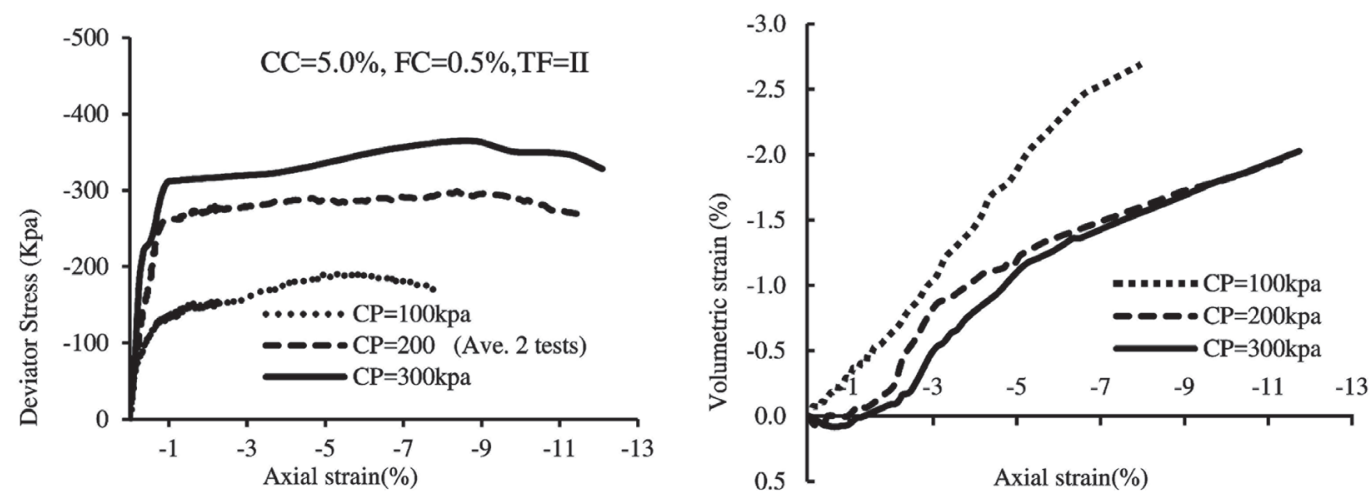

(c)

Fig. 8 Stress-strain and volume change behavior with $5.0 \%$ cement. (a) $\mathrm{FC}=0.0 \%$ (b) $\mathrm{FC}=0.5 \%, \mathrm{TF}=\mathrm{I}$ (c) $\mathrm{FC}=0.5 \%$, TF $=\mathrm{II}$
This occurrence is usually due to the large shear band in strains above $3 \%$ with regard to the focus of stress on the membrane in the location of shear band. However, the conclusion made from this diagram is that the reduction in brittleness index in fibers with a greater diameter is a little bit more than fibers with smaller diameter. Overall, it can be concluded that two parameters of confining pressure and fibers result in a reduced brittleness index of cement-treated sand and with an increase in both parameters, especially fibers, the brittleness of materials considerably decreases.$$
\text { ) }
$$ 
Fig. 10 shows the effects of peak deviatoric tensile stress versus the fiber aspect ratio logarithm (fiber length divided by fiber diameter) in order to consider the effect

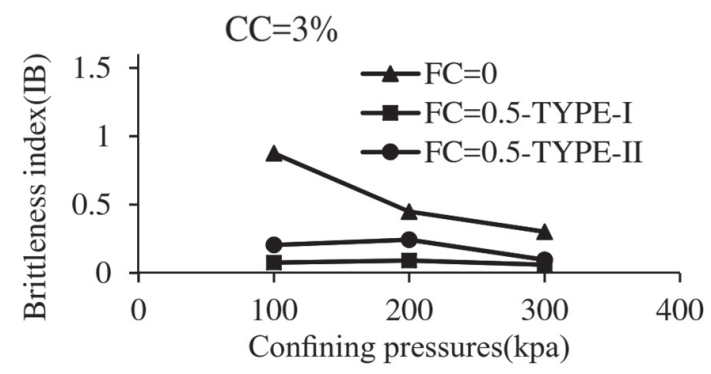

(a)

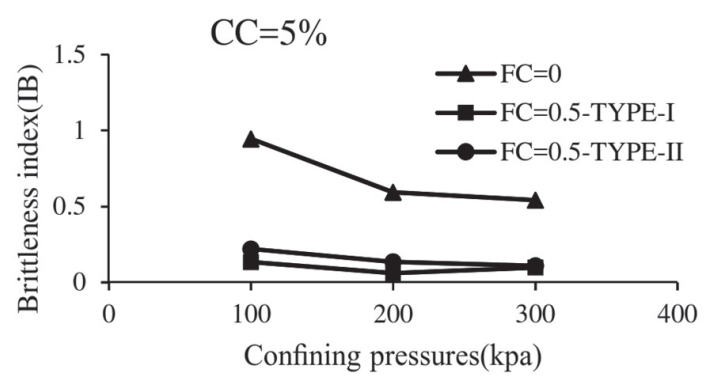

(b)

Fig. 9 The effects of brittleness index versus confining pressure and type of fiber; (a) $\mathrm{CC}=3.0 \%$; (b) $\mathrm{CC}=5.0 \%$

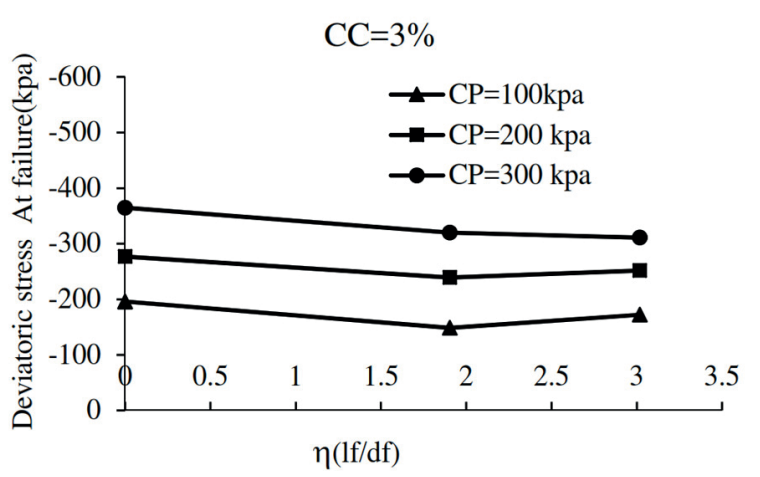

(a)

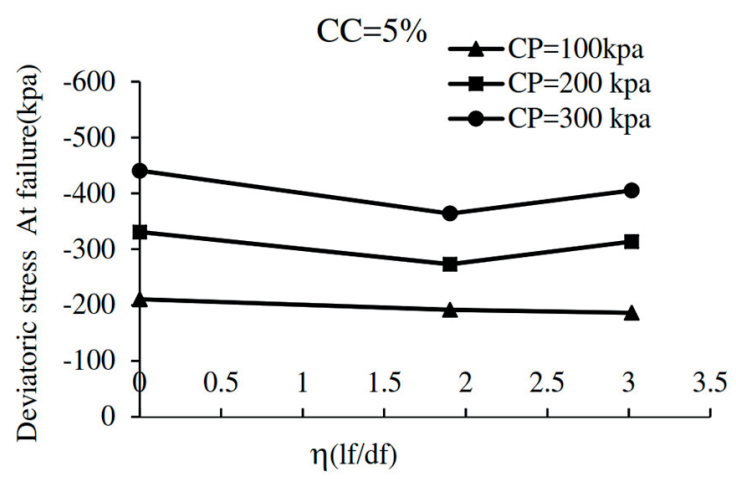

(b)

Fig. 10 Changes in tensile strength against confining pressure and type of fiber; (a) $\mathrm{CC}=3.0 \%$; (b) $\mathrm{CC}=5.0 \%$ of fiber diameter, cement percentages and changes in confining pressure. As it was previously mentioned, due to the decrease in cement bond by adding fibers, the ultimate deviatoric stress decreases and more interestingly, with an increase in aspect ratio (reduced fiber diameter) the drop becomes negligible. This might be because with an increase in aspect ratio of fiber, the reduction in cement bond is considerably lower.

It is well known that fiber results in reduced peak deviatoric tensile stress of cement-treated sand, while it increases strain in peak deviatoric tensile stress and residual deviatoric tensile stress. If we pay closer attention to Fig. 11, we will notice the effects of fiber on strain in peak deviatoric tensile stress. The simultaneous effect of cement percentage and fiber diameter on increases of strain in peak deviatoric tensile stress is $70 \%$ more than other parameters. Certainly, due to the accumulation of cementtreated grains and the formation of bigger grains, the rate of friction and involvement with thicker fibers enhanced. The effect of increases in confining pressure in both 3 and $5 \%$ cement is approximately the same and with an increase in confining pressure, peak strain also increases.

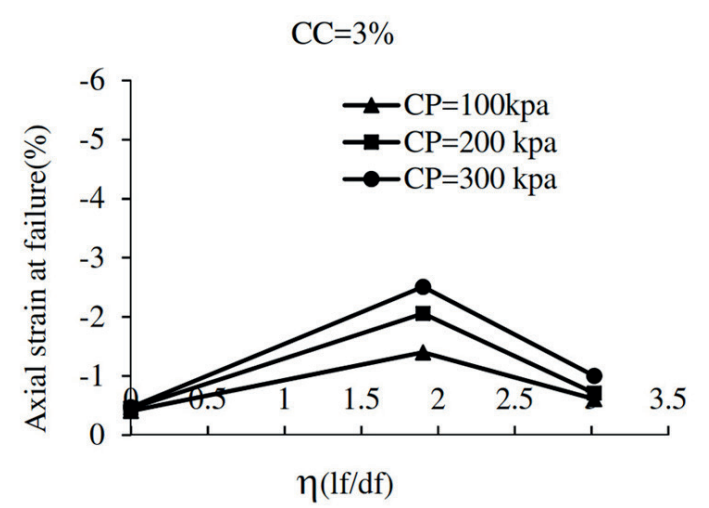

(a)

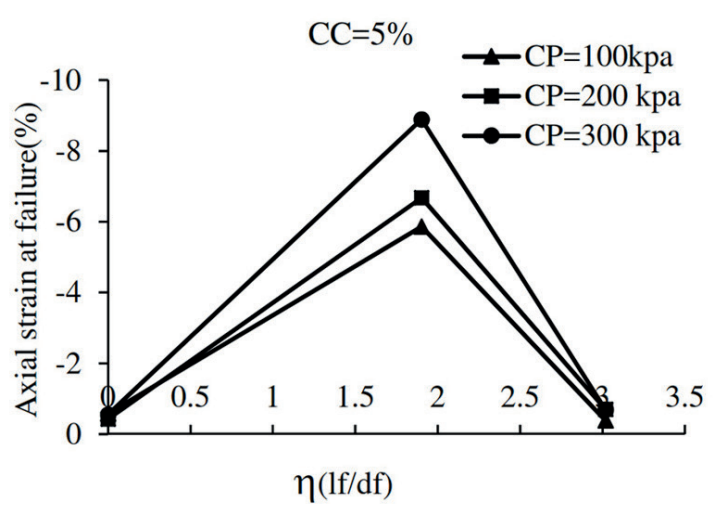

(b)

Fig. 11 Axial strain changes in failure stress with changes in confining pressure and type of fiber; (a) $\mathrm{CC}=3.0 \%$; (b) $\mathrm{CC}=5.0 \%$ 


\subsection{Stiffness}

In defining initial stiffness, and stiffness in 50\% tension and maximum tensile stress, secant stiffness was used. Secant stiffness is equal to the slope of the connecting line from the center of the stress-strain curve to a point on the curve at the considered stress or strain. Fig. 12(a) shows the changes in initial stiffness against effects of fiber type and confining pressure for samples with 5\% cement. As it is observed, initial stiffness is reduced with the addition of fibers and this reduction is much greater for fibers with greater diameter. Considering that after initial deformation, polypropylene fibers accumulate in order to confront probable stresses, thus fibers with thicker diameter become involved in lower stresses and result in more reduced stiffness of cement-treated sands.

In order to compare the effects of fiber on stiffness by considering greater stress, secant stiffness for 50\% maximum tensile stress was carried out $\left(\mathrm{E}_{50 \%}\right)$. Fig. 12(b) shows changes in stiffness compared to changes in fiber diameter and confining pressure. As observed in this figure, the effects of fiber diameter on reducing stiffness by $50 \%$ the maximum tensile stress for fibers with greater diameter is completely evident and shows that with an increase in fiber diameter, initial stiffness and stiffness in stress of $50 \%$
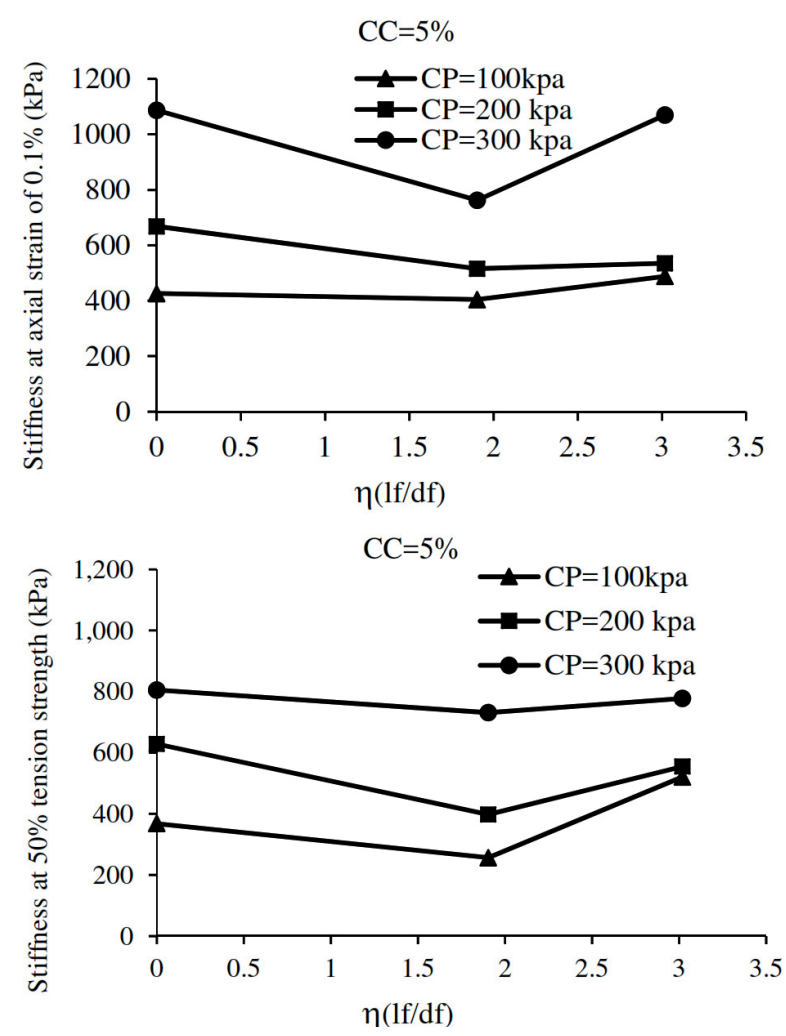

Fig. 12 Changes in initial stiffness and Stiffness at 50\% tension strength of samples with $5 \%$ cement with changes in confining pressure and type of fiber reduces by 30 to $50 \%$ depending on the confining pressure. According to Figs. 7(a) and (b), with an increase in confining pressure, initial stiffness and stiffness in tension at $50 \%$ of the maximum tension increases. Overall, it can be concluded that the addition of fiber reduces cementtreated sand samples stiffness, indicating ductile behavior.

\subsection{Energy absorption}

In this study, in order to evaluate the brittle and ductile failure modes, the concept of toughness was used, which indicates the capacity of materials in the amount of absorbed energy and transformation in plastic before failure. With regard to the static experimental conditions, toughness is equal to the area below the stress-strain curve up to the failure point. Failure point was defined as the amount of reduced stress from peak stress by $25 \%$ [41]. In a number of tests, since perforation of the membrane tension does not reach the failure point, the remaining residual stresses were considered as failure stress. Fig. 13 shows the changes in energy absorption with regard to variables including fiber diameter, confining pressure, and percentage of cement. According to the Fig. 13, absorbed energy for 5\% cement is greater than $3 \%$ cement and with an increase in confining pressure, absorbed energy increases greatly. The effect of fiber diameter and confining pressure on energy absorption is noteworthy in this diagram.

With an increase in confining pressure and fiber diameter, the energy absorption rate increases compared to fibers with lower diameter, especially in 5\% cement. This might be interpreted such that when confining pressure increases, friction between cement-treated soil grains and fiber increases. On the other hand, tensile forces increase energy absorption due to the adequate tensile resistant characteristic of fiber. This issue will intensify when fiber diameter grows and will result in more cement-treated soil grains to accumulate for confronting applied tensile stress.

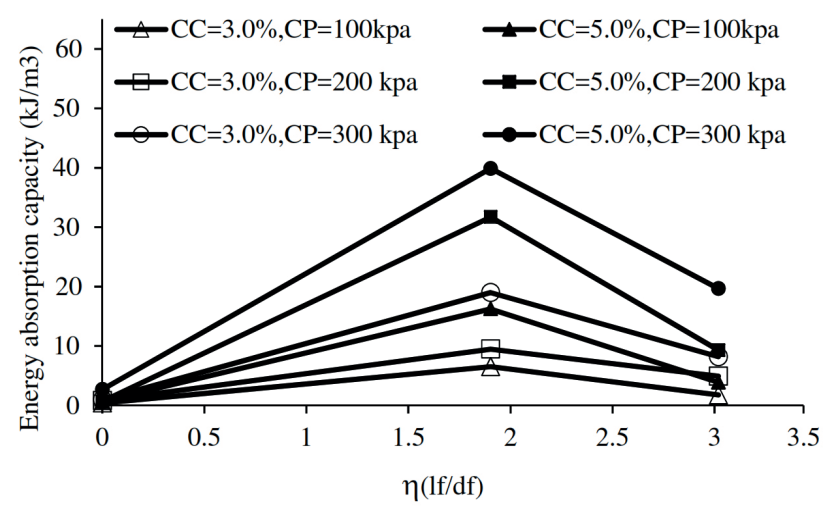

Fig. 13 Changes in energy absorption up to failure point versus effects of fiber diameter 
This is while the fracture mode diagram shown in Fig. 6 indicates that the fiber overlap along the length of the sample and its fracture from the weakest point has resulted in rapid friction of fibers with applied tensile stress and fracture spreads to other parts of the sample, which occurs in numerous parts of the sample, causing maximum energy adsorption.

Fig. 14 shows the effects of normalized energy adsorption in each strain divided by the overall energy absorbed in $3 \%$ strain in cement content of $5 \%$ and confining pressure of $100 \mathrm{Kpa}$. The sample slope without fiber changes after $0.8 \%$ strain and continues with a stable slope, which indicates the higher energy absorption rate at low strain. This is while the slope of diagrams with fiber is more uniform and with an increase in axial strain, absorbed energy also increases accordingly. If a line is depicted parallel to the horizontal axis at any height of Fig. 14, it can be concluded that the energy absorption rate in each strain for fibers with bigger diameters will be greater than smaller diameters and both will be greater than the sample without fiber.

\subsection{Failure envelopes and strength parameters}

Fig. 15 shows the failure envelopes resulting from direct tension in triaxial conditions with linear regression. The failure envelopes might not be linear for cement-fiber reinforced sand. However, with regard to adequate regression of above 90 percent, it can be a good estimate of cement-fiber reinforced sand parameters. By comparing the internal friction angle and cohesion intercept for cement-fiber reinforced sand at different diameters in Fig. 16, it can be concluded that by adding fibers, cohesion decreases and this decrease is greater for thicker fibers. The reason for a reduction in cohesion factor might be the reduced bond between soil grains due to fibers and in fact connections from cement due to added fiber have become less and

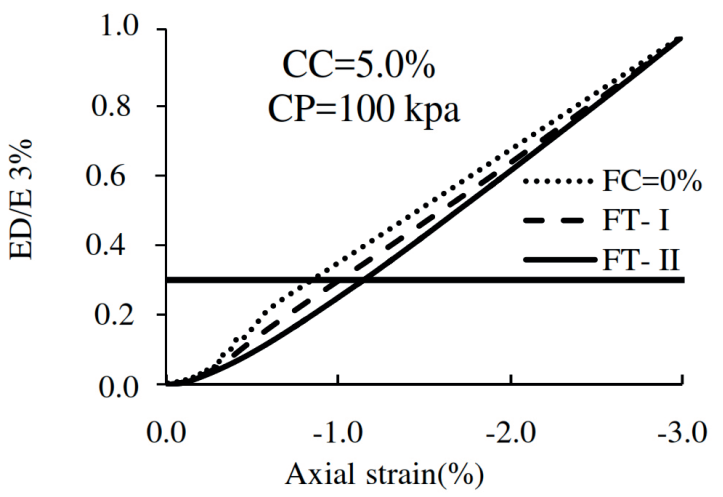

Fig. 14 Changes in normalized absorbed energy compared to axial strain with effect of fiber diameter

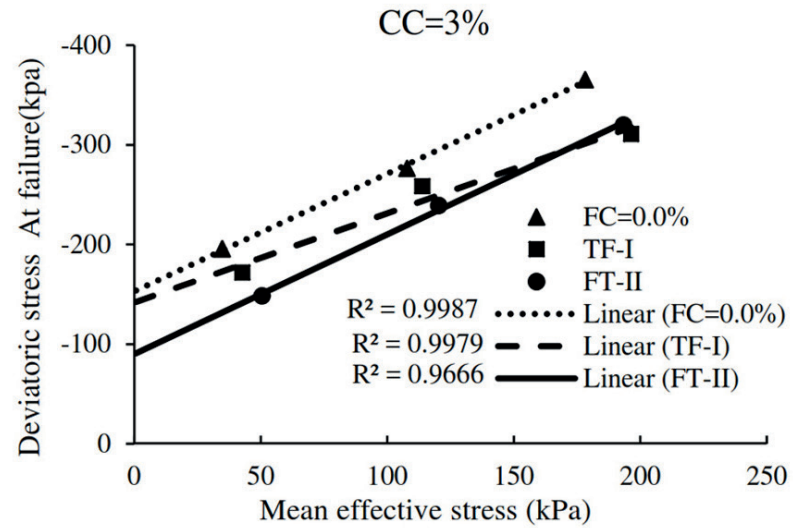

(a)

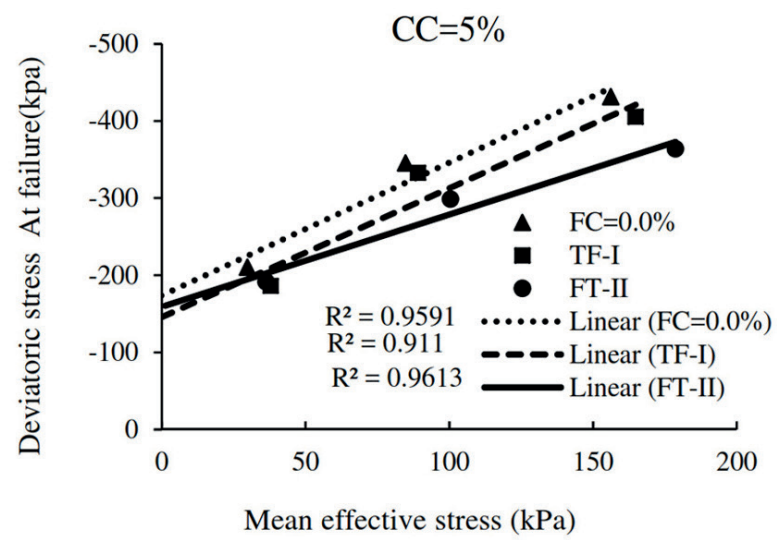

(b)

Fig. 15 Failure envelopes for cement-treated sand reinforced with fibers compared to percentage of cement; (a) $\mathrm{CC}=3 \%$; (b) $\mathrm{CC}=5 \%$

reduced the cohesion factor. With an increase in fiber diameter, this reduction will be greater whereas for type 2 fibers, almost $15 \%$ and for type 1 fibers almost a $9 \%$ decrease in cohesion is obtained. However, the internal friction angle increases by adding fiber and the greater the fiber diameter, the bigger the friction angle. By comparing the increase in friction angle in Fig. 16(b) it can be observed that this parameter has been enhanced for fibers with a diameter greater than $30 \%$ and for those with a diameter less than $11 \%$. It is noteworthy that with an increase in the percentage of cement both strength parameters of soil increase.

Fig. 17 shows changes in the principal stress ratio in failure stress and residual stress compared to changes in dimensional ratio and effects of percentage and cement and confining pressure. With an increase in confining pressure, both of the main stress ratios decrease at the failure and residual stress. However, with the addition of fiber, the ratio of main stress in failure decreases, while it increases in residual stress. The effect of cement percentage on the ratio of failure and residual stress has been similar and both increase with an increase in cement percentage. 


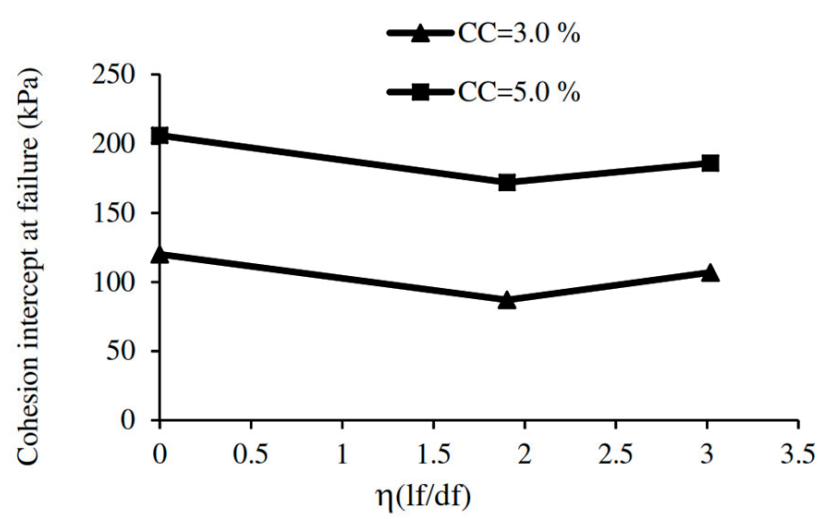

(a)

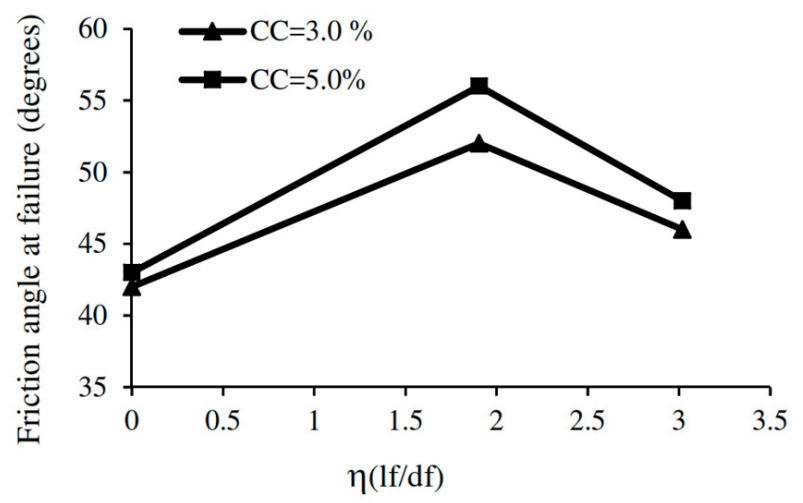

(b)

Fig. 16 Changes in (a) the cohesion intercept; (b) internal friction coefficient compared to the fiber dimensional ratio

\section{Conclusions}

Due to the significance of cement-fiber reinforced sand tensile behavior in engineering projects and its high impact in the design of geotechnical structures, with regard to carrying out direct tension tests under triaxial loading conditions, the results of this study can be beneficial for designers and geotechnical engineers as follows:

The results obtained from Fig. 6 show that the fracture point does not occur at a specific point in the sample length and the random fracture indicates homogeneity in sample preparation using a vibration method.

Adding fibers results in changes in fracture mode from tensile to shear mode, and when the fiber diameter increases, the fracture type transforms to multiple shear fracture. The increase in shear bandwidth is greater with the addition of fiber and the effect of increasing fiber diameter and decreasing cement percentage compared to other parameters.

The peak tensile stress for fiber-treated samples in all cement-treated sand samples is decreased, but the residual stress and failure strain increase and the material behavior changes from brittle to ductile state.

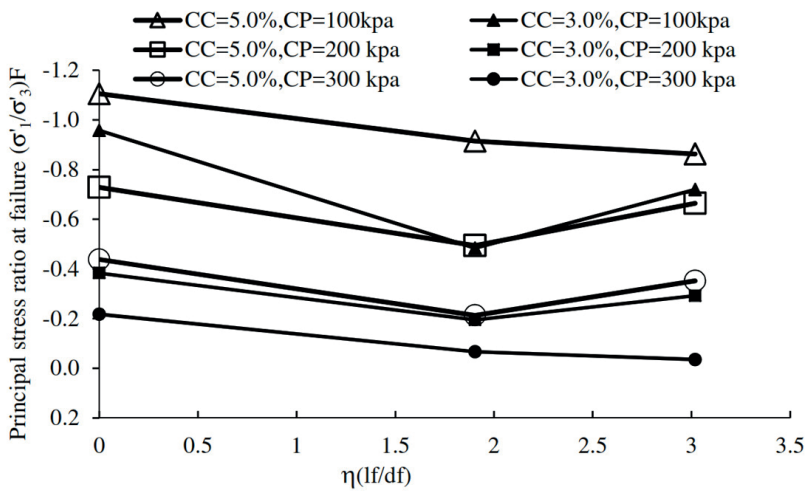

(a)

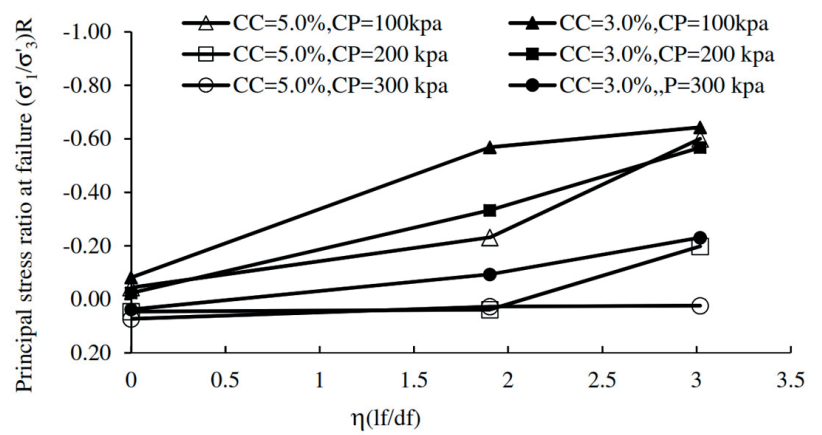

(b)

Fig. 17 Changes in main stress ratio in (a) peak stress; (b) residual stress

The initial stiffness and stiffness at $50 \%$ peak tensile stress is reduced with the addition of fibers, especially thicker fibers. Also, evaluating the brittleness index shows that fiber-reinforced samples have lower stiffness compared to those samples without fiber.

Toughness and absorbed energy to the failure point of fiber-treated samples were greater than cement-treated sand samples and the effect of fibers with a bigger diameter was greater than fibers with a smaller diameter. However, it is noteworthy that with an increase in confining pressure and percentage of cement, the rate of absorbed energy increases, while increasing fiber diameter is the most effective parameter in increasing energy absorption to the failure point.

The cohesion intercept in fiber-reinforced samples decreases due to a decrease in the cement bond by a maximum of $15 \%$ for type 2 fibers and by a maximum of $9 \%$ for type 1 fibers. However, the internal friction angle increases with the addition of fibers to cement-treated sand samples by a maximum of $30 \%$ for type 2 fibers and $11 \%$ for type 1 fibers.

Even though the main stress ratio decreases for the peak with the addition of fiber, this ratio significantly increases for residual stress with the addition of fibers, especially thicker fibers. 


\section{References}

[1] Kitazume, M., Maruyama, K. "Internal stability of group column type deep mixing improved ground under embankment loading", Soils and Foundations, 47(3), pp. 437-455, 2007. https://doi.org/10.3208/sandf.47.437

[2] Tokimatsu, K., Mizuno, H., Kakurai, M. "Building damage associated with geotechnical problems", Soils and Foundations, 36, pp. 219-234, 1996.

https://doi.org/10.3208/sandf.36.Special_219

[3] Namikawa, T., Koseki, J., Suzuki, Y. "Finite element analysis of lattice-shaped ground improvement by cement-mixing for liquefaction mitigation", Soils and Foundations, 47(3), pp. 559-576, 2007. https://doi.org/10.3208/sandf.47.559

[4] Khosravi, M., Boulanger, R. W., Tamura, S., Wilson, D. W., Olgun, C. G., Wang, Y. "Dynamic centrifuge tests of soft clay reinforced by soil-cement grids", Journal of Geotechnical and Geoenvironmental Engineering, 142(7), Article number: 04016027, 2016. https://doi.org/10.1061/(ASCE)GT.1943-5606.0001487

[5] Shukla, S. K. "Engineering Behaviour of Fibre-Reinforced Soil", In: Fundamentals of Fibre-Reinforced Soil Engineering, Springer, Singapore, 2017, pp. 45-110.

https://doi.org/10.1007/978-981-10-3063-5_3

[6] Saxena, S. K., Lastrico, R. M. "Static properties of lightly cemented sand", Journal of the Geotechnical Engineering Division, 104(12), pp.1449-1464, 1978.

https://doi.org/10.1061/AJGEB6.0000728

[7] Clough, G. W., Sitar, N., Bachus, R. C., Rad, N. S. "Cemented sands under static loading", Journal of the Geotechnical Engineering Division, 107(6), pp. 799-817, 1981.

https://doi.org/10.1061/AJGEB6.0001152

[8] Consoli, N. C., Rotta, G. V., Prietto, P. D. M. "Influence of curing under stress on the triaxial response of cemented soils", Géotechnique, 50(1), pp. 99-105, 2000. https://doi.org/10.1680/geot.2000.50.1.99

[9] Leroueil, S., Vaughan, P. R. "The general and congruent effects of structure in natural soils and weak rocks", Géotechnique, 40(3), pp. 467-488, 1990. https://doi.org/10.1680/geot.1990.40.3.467

[10] Coop, M. R., Atkinson, J. H. "Discussion: The mechanics of cemented carbonate sands", Géotechnique, 44(3), pp. 533-537, 1994. https://doi.org/10.1680/geot.1994.44.3.533

[11] Schnaid, F., Prietto, P. D. M., Consoli, N. C. "Characterization of cemented sand in triaxial compression", Journal of Geotechnical and Geoenvironmental Engineering, 127(10), pp. 857-868, 2001. https://doi.org/10.1061/(ASCE)1090-0241(2001)127:10(857)

[12] Haeri, S. M., Hamidi, A., Tabatabaee, N. "The effect of gypsum cementation on the mechanical behavior of gravely sands", Geotechnical Testing Journal, 28(4), pp. 380-390, 2005. https://doi.org/10.1520/GTJ12574

[13] Consoli, N. C., Cruz, R. C., da Fonseca, A. V., Coop, M. R. "Influence of cement-voids ratio on stress-dilatancy behavior of artificially cemented sand", Journal of Geotechnical and Geoenvironmental Engineering, 138(1), pp. 100-109, 2012.

https://doi.org/10.1061/(ASCE)GT.1943-5606.0000565
[14] Namikawa, T., Koseki, J. "Experimental determination of softening relations for cement-treated sand", Soils and foundations, 46(4), pp. 491-504, 2006.

https://doi.org/10.3208/sandf.46.491

[15] Namikawa, T., Koseki, J. "Evaluation of tensile strength of cementtreated sand based on several types of laboratory tests", Soils and Foundations, 47(4), pp. 657-674, 2007. https://doi.org/10.3208/sandf.47.657

[16] Sarfarazi, V., Ghazvinian, A., Schubert, W., Nejati, H. R., Hadei, R. "A new approach for measurement of tensile strength of concrete", Periodica Polytechnica Civil Engineering, 60(2), pp. 199-203, 2016. https://doi.org/10.3311/PPci.8328

[17] Namikawa, T., Hiyama, S., Ando, Y., Shibata, T. "Failure behavior of cement-treated soil under triaxial tension conditions", Soils and Foundations, 57(5), pp. 815-827, 2017. https://doi.org/10.1016/j.sandf.2017.08.011

[18] Gray, D. H., Ohashi, H. "Mechanics of fiber reinforcement in sand", Journal of Geotechnical Engineering, 109(3), pp. 335-353, 1983. https://doi.org/10.1061/(ASCE)0733-9410(1983)109:3(335)

[19] Consoli, N. C., Dal Casagrande, M., Coop, M. R. "Effect of fiber reinforcement on the isotropic compression behavior of a sand", Journal of Geotechnical and Geoenvironmental Engineering, 131(11), pp. 1434-1436, 2005. https://doi.org/10.1061/(ASCE)1090-0241(2005)131:11(1434)

[20] Consoli, N. C., Dal Toé Casagrande, M., Coop, M. R. "Behavior of a fiber-reinforced sand under large shear strains", In: Proceedings of the 16th International Conference on Soil Mechanics and Geotechnical Engineering, Osaka, Japan, 2005, pp. 1331-1334. https://doi.org/10.3233/978-1-61499-656-9-1331

[21] Latha, G. M., Murthy, V. S. "Effects of reinforcement form on the behavior of geosynthetic reinforced sand", Geotextiles and Geomembranes, 25(1), pp. 23-32, 2007. https://doi.org/10.1016/j.geotexmem.2006.09.002

[22] Lovisa, J., Shukla, S. K., Sivakugan, N. "Shear strength of randomly distributed moist fibre-reinforced sand", Geosynthetics International, 17(2), pp. 100-106, 2010. https://doi.org/10.1680/gein.2010.17.2.100

[23] Ibraim, E., Diambra, A., Russell, A. R., Wood, D. M. "Assessment of laboratory sample preparation for fibre reinforced sands", Geotextiles and Geomembranes, 34, pp. 69-79, 2012. https://doi.org/10.1016/j.geotexmem.2012.03.002

[24] Tang, C.-S., Wang, D.-Y., Cui, Y.-J., Shi, B., Li, J. "Tensile strength of fiber-reinforced soil", Journal of Materials in Civil Engineering, 28(7), Article number: 04016031, 2016. https://doi.org/10.1061/(ASCE)MT.1943-5533.0001546

[25] Maher, M. H., Ho, Y. C. "Behavior of fiber-reinforced cemented sand under static and cyclic loads", Geotechnical Testing Journal, 16(3), pp. 330-338, 1993. https://doi.org/10.1520/GTJ10054J

[26] Consoli, N. C., Prietto, P. D. M., Ulbrich, L. A. "Influence of fiber and cement addition on behavior of sandy soil", Journal of Geotechnical and Geoenvironmental Engineering, 124(12), pp. 1211-1214, 1998. https://doi.org/10.1061/(ASCE)1090-0241(1998)124:12(1211) 
[27] Consoli, N. C., Montardo, J. P., Donato, M., Prietto, P. D. "Effect of material properties on the behaviour of sand-cement-fibre composites", Proceedings of the Institution of Civil Engineers - Ground Improvement, 8(2), pp. 77-90, 2004. https://oi.org/10.1680/grim.2004.8.2.77

[28] Consoli, N. C., Vendruscolo, M. A., Fonini, A., Dalla Rosa, F. "Fiber reinforcement effects on sand considering a wide cementation range", Geotextiles and Geomembranes, 27(3), pp. 196-203, 2009. https://doi.org/10.1016/j.geotexmem.2008.11.005

[29] Consoli, N. C., Bassani, M. A. A., Festugato, L. "Effect of fiber-reinforcement on the strength of cemented soils", Geotextiles and Geomembranes, 28(4), pp. 344-351, 2010. https://doi.org/10.1016/j.geotexmem.2010.01.005

[30] Consoli, N. C., Zortéa, F., de Souza, M., Festugato, L. "Studies on the dosage of fiber-reinforced cemented soils", Journal of Materials in Civil Engineering, 23(12), pp. 1624-1632, 2011. https://doi.org/10.1061/(ASCE)MT.1943-5533.0000343

[31] Hamidi, A., Hooresfand, M. "Effect of fiber reinforcement on triaxial shear behavior of cement treated sand", Geotextiles and Geomembranes, 36, pp. 1-9, 2013. https://doi.org/10.1016/j.geotexmem.2012.10.005

[32] Festugato, L., Menger, E., Benezra, F., Kipper, E. A., Consoli, N. C. "Fibre-reinforced cemented soils compressive and tensile strength assessment as a function of filament length", Geotextiles and Geomembranes, 45(1), pp. 77-82, 2017. https://doi.org/10.1016/j.geotexmem.2016.09.001

[33] Festugato, L., da Silva, A. P., Diambra, A., Consoli, N. C., Ibraim, E. "Modelling tensile/compressive strength ratio of fibre reinforced cemented soils", Geotextiles and Geomembranes, 46(2), pp. 155-165, 2018. https://doi.org/10.1016/j.geotexmem.2017.11.003

[34] Consoli, N. C., De Moraes, R. R., Festugato, L. "Split tensile strength of monofilament polypropylene fiber-reinforced cemented sandy soils", Geosynthetics International, 18(2), pp. 57-62, 2011. https://doi.org/10.1680/gein.2011.18.2.57
[35] ASTM "ASTM D2487-17 Standard practice for classification of soils for engineering purposes (unified soil classification system)", American Society for Testing and Materials, West Conshohocken, PA, USA, 2011. https://doi.org/10.1520/D2487-11

[36] Ladd, R. S. "Preparing test specimens using undercompaction", Geotechnical Testing Journal, 1(1), pp. 16-23, 1978. https://doi.org/10.1520/GTJ10364J

[37] Koseki, J., Sato, T., Mihira, S., Takeya, N., Yoshizawa, M. "Comparison of tensile strength of cement treated sand by various test methods", [pdf] In: International Conference on Deep Mixing Best Practice and Recent Advances, Stockholm, Sweden, 2005, pp. 95-100. Available at: https://www.sgi.se/globalassets/publikationer/svensk-djupstabilisering/sd-r13-v1-1.pdf

[38] Ampadu, S. K., Tatsuoka, F. "Effect of setting method on the behaviour of clays in triaxial compression from saturation to undrained shear", Soils and Foundations, 33(2), pp. 14-34, 1993. https://doi.org/10.3208/sandf1972.33.2_14

[39] Skempton, A. W. "The pore-pressure coefficient in saturated soils", Géotechnique, 10(4), pp. 186-187, 1960. https://doi.org/10.1680/geot.1960.10.4.186

[40] Stacho, J., Sulovska, M., Slavik, I. "Determining the Shear Strength Properties of a Soil-geogrid Interface Using a Large-scale Direct Shear Test Apparatus", Periodica Polytechnica Civil Engineering, 64(4), pp. 989-998, 2020. https://doi.org/10.3311/PPci.15766

[41] Georgees, R. N., Hassan, R. A., Evans, R. P., Jegatheesan, P. "An evaluation of performance-related properties for granular pavement materials using a polyacrylamide additive", International Journal of Pavement Engineering, 19(2), pp. 153-163, 2018. https://oi.org/10.1080/10298436.2016.1172710 